\title{
Liber: alternativa para publicação eletrônica
}

\section{Karina Moutinho}

Pesquisadora do projeto Narrativas Digitais do Virtus - Laboratório de Hipermídia, mestre em psicologia cognitiva pela UFPE e professora substituta da UFPE.

E-mail: karinam@hotlink.com.br

\section{Paulo C. Cunha Filho}

Professor doutor vinculado ao Departamento de Comunicação Social da UFPE, coordenador do projeto Narrativas Digitais e coordenador geral do Virtus - Laboratório de Hipermídia. E-mail:paulo@npd.ufpe.br

\begin{abstract}
Alessandra Marques de Lima
Bolsista do Projeto Narrativas Digitais do Virtus - Laboratório de Hipermídia e graduanda do Curso de Design da UFPE.

E-mail: amarqueslima@bol.com.br

Virtus - Laboratório de Hipermídia da Universidade Federal de Pernambuco

Biblioteca Central - 2o andar - Avenida dos Reitores, s/n Cidade Universitária - Recife - PE Brasil CEP: 50670-901

Fone: (0**81) 3271-8963/3271-8964 - Fax: (0**81) 3271-8964

www.virtus.ufpe.br

virtus@npd.ufpe.br
\end{abstract}

\section{Resumo}

Este artigo tem por objetivo discutir características da publicação digital, apontando-se alterações que o suporte eletrônico proporciona desde a redação até a publicação, interferindo também na relação entre autor e usuários. Apresenta-se também o Liber, projeto desenvolvido pelo Virtus - Laboratório de Hipermídia da UFPE, destacando-se suas características principais e sua contriuição no campo das publicações digitais.

\section{Palavras-chave}

Publicação eletrônica; Publicação impressa; Arquivos abertos; Avaliação de pares; Liber; Virtus

\section{Liber: an alternative for eletronic publishing}

\begin{abstract}
This paper aims the discussion of the characteristics of eletronic publishing by identifying changes provided by electronic support - from composition to publication - on the relationship between authors and readers. It also presents Liber, a project developed by Virtus - UFPE's Hypermidia Laboratory, standing out its main characteristics and its contributions in the field of the eletronic publishing.
\end{abstract}

\section{Keywords}

Eletronic publishing; Paper publishing; Open archives; Peer review; Liber; Virtus

\section{TECNOLOGIA E PUBLICAÇÃO}

Os instrumentos tecnológicos têm sempre interferido no processo de publicação de informações, de maneira que progressivamente ferramentas diversas têm mediado a relação entre o autor e o usuário da informação. Tomese como referência os tipos de suporte usados neste processo de publicação ao longo do tempo:

\begin{tabular}{|c|c|c|c|c|c|}
\hline Autor & Papel & Película & Fita magnética & $\begin{array}{l}\text { Superfície } \\
\text { digital }\end{array}$ & Usuário \\
\hline & $\begin{array}{l}\text { onde } \\
\text { podem } \\
\text { ser } \\
\text { gravados } \\
\text { textos ou } \\
\text { imagens em } \\
\text { Processos de } \\
\text { impressão }\end{array}$ & $\begin{array}{l}\text { imagens } \\
\text { podem } \\
\text { ser gravadas } \\
\text { por meio de } \\
\text { um processo } \\
\text { fotoquímico } \\
\text { (filme } \\
\text { fotográfico) }\end{array}$ & $\begin{array}{l}\text { imagens e/ou } \\
\text { sons } \\
\text { podem ser } \\
\text { gravados } \\
\text { por meio de } \\
\text { processos } \\
\text { eletrônicos }\end{array}$ & $\begin{array}{l}\text { A informação } \\
\text { é gravada a } \\
\text { partir } \\
\text { de processos } \\
\text { ópticos digitais } \\
\text { (disquete, CD, } \\
\text { DVD, HD) }\end{array}$ & \\
\hline
\end{tabular}

Dentre estes instrumentos, o suporte digital é exatamente aquele que proporciona o tipo de publicação eletrônica e que tem aparecido em número crescente e sobre os mais diferentes tipos de informação, como textos acadêmicos e literários.

O Directory of Electronic Journals, Newsletters and Academic Discussion Lists da Association of Researches Libraries - ARL ${ }^{1}$ identificava, em 1995, cerca de 675 publicações científicas eletrônicas do tipo jornais, revistas, entre outras. A última revisão do diretório, que data de 1997, aponta que este tipo de publicação soma um total de 3.414, significando um aumento de mais de $80 \%$ deste tipo de publicação eletrônica em dois anos.

No campo literário, é possível encontrar hoje sites que dispõem de textos completos de autores clássicos e contemporâneos para download gratuito. A Biblioteca Miguel de Cervantes ${ }^{2}$ dispõe de 5 mil livros em espanhol e tem a pretensão de disponibilizar cerca de 30 mil nos próximos anos. Durante seus primeiros 18 meses de funcionamento (teve seu início em 1999), a biblioteca já obteve cerca de 30 milhões de visitas. Acervo maior já dispõe o site Literature Online ${ }^{3}$, que dispõe de cerca de 330 mil textos variados - poesia, prosa, biografias a respeito de 250 autores de língua inglesa, desde a Idade Média até a atualidade. No Brasil, o site Literatura Brasileira: Textos Literários em Meio Eletrônico ${ }^{4}$ possui, em seu acervo, obras que datam desde o século XVI ao século XX, contando com textos completos de Raul Pompéia, Machado de Assis, Euclides da Cunha, entre outros. 


\section{O ELETRÔNICO E O IMPRESSO}

Este aumento progressivo de publicações eletrônicas se faz diante das expressivas vantagens que a publicação eletrônica proporciona. Os custos de produção e de distribuição podem ser consideravelmente menores que outras formas de publicação, como os de impressos tradicionais. Assim, admite-se que será mais simples disponibilizar textos que não conseguem publicação impressa. Para os produtos na Internet, existe maior facilidade (de preço e de rapidez) de acesso e de publicação dos textos, desde que o usuário disponha de computador (ou outro equipamento de leitura digital) e de conexão.

Já são conhecidos também os argumentos em termos do poder de estocagem que a informação possui no suporte digital, tais como em disquetes e CD-ROM's. De acordo como Andrew Odlyzko ${ }^{5}$, toda publicação anual no campo da matemática em todo o mundo (em torno de 50 mil artigos) pode ser inserida em um disco rígido de 2.5 gigabytes, o que, comparativamente, não excede o valor de uma assinatura de uma revista impressa.

Este tipo de armazenamento da informação alimenta ainda o sonho ocidental da biblioteca universal, presente desde Alexandria, e que se tornou de difícil realização diante do crescimento da produção impressa, com o aumento das tiragens dos livros, da produção dos jornais e multiplicação de periódicos e revistas. Para Chartier ${ }^{6}$,

"com o texto eletrônico, a biblioteca universal torna-se imaginável (senão possível), sem que, para isso, todos os livros estejam reunidos em um único lugar. Pela primeira vez, na história da humanidade, a contradição entre o mundo fechado das coleções e o universo infinito do escrito perde seu caráter inelutável”.

\section{DA REDAÇÃO À PUBLICAÇÃO}

As publicações impressas, embora consagradas, exigem um processo convencionalmente demorado e incômodo para grande parte de escritores. Arlindo Machado ${ }^{7}$ fala de um abismo entre redação e publicação, onde a distância entre ambos cresce exponecialmente, na medida em que os progressos no pensamento científico se fazem de forma cada vez mais rápida. Para o autor, trata-se do calcanharde-aquiles da publicação impressa.

Este autor destaca ainda que um artigo científico a ser publicado em periódico internacional pode demorar até três anos para ser disponibilizado ao público. No percurso entre a redação e a divulgação, o autor submete seu texto à editora, este é avaliado por um corpo editoral que pode demorar cerca de um ano para definir sobre a publicação do artigo. Caso seja aceito, o autor esperará agora a definição e impressão do exemplar em que o texto deva ser publicado. É exatamente esta demora que pode culminar com a defasagem da informação publicada, superada pela confirmação de novas hipóteses produzidas por outros autores ou até pelo mesmo autor, em pesquisas mais recentes. Vannevar Bush, em As We May Think, comenta: "As leis da genética de Mendel ficaram perdidas por uma geração porque sua publicação não alcançou os que seriam capazes de entendê-las e estendê-las".

Com as ferramentas eletrônicas, por sua vez, o autor pode disponibilizar o texto logo após este ser produzido. Dispondo de conhecimento tecnológico básico, qualquer usuário da Internet pode criar e manter um site e nele divulgar os mais variados textos, tais como poesias, contos e produções acadêmicas. A submissão, classificação e indexação dos artigos é feita automaticamente por meio de programas computacionais que consideram informações fornecidas pelo usuário/ autor; o texto pode ser disponibilizado pelo próprio autor, imediatamente após sua confecção, dispensando, assim, o longo processo de revisão de pares (peer review) comumente adotado em publicações científicas para atestar a qualidade das produções acadêmicas (por exemplo, Sena ${ }^{9}$ ).

Os arquivos abertos ou open archives são iniciativas que exploram exatamente este tipo de publicação. Estes ambientes agregam eprints ou preprints ("artigos técnicos em versão preliminar antecedente à publicação impressa em jornal”10) de áreas diversas e estão abertos à consulta pública e gratuita. Bastante reconhecido e visitado é o arXiv ${ }^{11}$, este último criado por Paul Ginsparg e mantido pelo Laboratório Nacional de Los Alamos, Novo México, e que se tornou um repositório global de artigos não revisados pelos pares especificamente nas áreas de física, matemática, ciência da computação e ciências não-lineares.

Ao tempo despendido para avaliação do texto submetido pode somar-se ainda uma segunda problemática. Fatores diversos, como as opções mercadológicas das editoras, interferem diretamente sobre a qualidade das publicações realizadas, de forma que escritores principiantes e acadêmicos renomados têm encontrado dificuldades para ver publicada sua obra em formato impresso. 
De acordo com Robert Darnton, professor da Universidade de Princeton, estudos realizados pela American Historical Association (AHA) e instituições de pesquisa tais como Research Library Group demonstram que é quase impossível a um historiador em início de carreira publicar sua dissertação em áreas tais como história da África e América Latina colonial ${ }^{12}$. Em artigo publicado na Folha de S. Paulo, Sérgio Augusto ${ }^{13}$ fala do caso Gregory S. Brown, professor-assintente de história da Universidade de Nevada, que produziu tese bastante elogiada sobre o prestígio de intelectuais franceses no iluminismo. A despeito do reconhecido valor da obra, a tese foi recusada por várias editoras universitárias.

Algumas alternativas têm sido criadas pretendendo-se superar esta problemática utilizando-se exatamente os suportes digitais. No campo literário, vários sites hoje abrigam produções já recusadas para publicação impressa e que têm conquistado o leitor/usuário da world wide web. O Literatura Sul-Rio-Grandense ${ }^{14}$ divulga textos de escritores gaúchos tanto ilustres, quanto pouco conhecidos. Érico Veríssimo, Zeca Blau e Meyer partilham este ambiente virtual, que vem tendo grande repercussão, especialmente sobre os conterrâneos. Alguns sites evidenciam toda esta problemática e convidam os usuários a conhecer outros autores, que tentam superar os obstáculos à publicação. Assim coloca Hélio Pólvora, no Jornal de Contos: ${ }^{15}$

"A intenção fundamental é vencer barreiras: a do livro que circula mal, a da falta de divulgação adequada, a dos críticos e resenhistas discriminadores, a da escassez de intercâmbio. Habitue-se, aqui, a ler outros autores. Eles não são seus concorrentes. São contistas que enfrentam obstáculos - entre os quais o preconceito editorial contra o gênero conto - e que estão no mesmo barco..." (ver também Moraes ${ }^{16}$ ).

No âmbito acadêmico, iniciativas têm sido realizadas com o propósito de facilitar a publicação de trabalhos científicos. $\mathrm{O}$ projeto Gutenberg-e $\mathrm{e}^{17}$, promovido pela American Historical Association e com apoio da Fundação Andrew W. Mellon, promove uma competição em que são premiadas as melhores dissertações em história versando sobre áreas com temáticas raramente abordadas. O prêmio deve ser utilizado para conversão do trabalho a um formato eletrônico, podendo, assim, atingir um amplo número de leitores.

Também neste sentido, periódicos eletrônicos têm sido desenvolvidos por pesquisadores em todo mundo em uma quantidade cada vez maior. Em artigo objetivando analisar o interesse de revistas brasileiras e francesas de biblioteconomia e ciências da informação pela revista eletrônica, Menezes \& Couzinet ${ }^{18}$ destacam a posição de Yves F. Le Coadic. Para este autor, tecnologias avançadas são importantes para que seja criado um tipo de publicação mais econômica e mais adequada às necessidades dos usuários: a revista eletrônica.

"A revista eletrônica permite, atualmente, uma difusão rápida e contínua dos artigos, acesso permanente, qualquer que seja o lugar onde a pessoa se encontre, e maiores possibilidades de pesquisa. A utilização de ligações hipertexto e um conjunto de documentos associados ao artigo, como comentários, por exemplo, enriquecem a pesquisa documentária. Y. Le Coadic conclui, portanto, que este novo meio da literatura científica tem um futuro promissor".

Este tipo de publicação está sendo bastante utilizado no universo acadêmico, e muitas revistas hoje já nascem exclusivamente eletrônicas, e, neste artigo, destaca-se ainda que a publicação científica brasileira deve inserir-se no movimento internacional de publicação eletrônica. Exatamente neste sentido, o IBICT está desenvolvendo o Arquivos Abertos ${ }^{19}$, um protótipo de open archives, destinado ao registro e à discussão de textos completos produzidos por pesquisadores que atuam nas áreas de ciência e tecnologia.

\section{INFORMAÇÃO ELETRÔNICA E RELAÇÃO AUTOR-USUÁRIOS}

Estas observações feitas sobre o processo de publicação, desde a produção da obra à exibição ou publicação propriamente dita, leva-nos exatamente a um outro aspecto, que diz da relação entre autor e usuário da informação. A este respeito, uma primeira e notória observação a ser feita diz do aumento do número de arquivos disponibilizados na web, facilmente acessíveis pelo usuário. Mais ainda, o usuário também pode ter uma relação mais estreita com o autor, que pode ser contatado por e-mails, por exemplo.

Um segundo aspecto refere-se mais especificamente à qualidade desta relação autor-usuário, o que requer algumas considerações sobre o texto eletrônico. $\mathrm{O}$ texto eletrônico pode ser revisado e renovado ou atualizado em um mesmo suporte, caracterizando-se, assim, como de estrutura aberta. Este tipo de texto pode manter-se disponível a estabelecer relações, enlaces com outros textos (que podem ser palavras, imagens, gráficos etc.), constituindo o hipertexto um tipo de texto repleto de "nós"20.

Em certos tipos de obras, esta caraterística do texto eletrônico faz-se notar pela participação contínua dos usuários, que interferem na definição do texto não somente pela decisão de que "nós" acessar, mas na 
construção de uma espécie de "texto cooperativo", no qual a intervenção dos usuários é requerida pelo autor. Tome-se como exemplo o Hipertramas ${ }^{21}$. Para construção de histórias, os administradores do site sugerem título e primeiros parágrafos. $\mathrm{O}$ usuário pode dar continuidade por meio de comentários enviados por e-mail.

No âmbito acadêmico, vale mencionar os Ambientes Virtuais de Estudo (AVE) desenvolvidos pelo Virtus Laboratório de Hipermídia da Universidade Federal de Pernambuco $^{22}$. Nestes sistemas de tecnologias de informação aplicados à educação via Internet, a interatividade é destacada como eficiente campo pedagógico: o sistema conta com ferramentas tais como "salas de bate-papo", para discussões em tempo real, e "fóruns", quando as discussões podem ser contínuas e assíncronas, por não exigirem hora marcada. Os AVEs possibilitam a construção progressiva do conteúdo da disciplina mediante participação ativa de professor e aluno, viabilizando a instalação de modelos pedagógicos que defendem a construção conjunta do saber ${ }^{23,24}$.

Tem cabido ao usuário, então, não apenas o papel de receptor de informações. Com poder de intervenção sobre o texto eletrônico, este tem a potencialidade constante de atualização, e, entre autor e usuário, pode-se realizar contínuos debates. O Psycholoquy ${ }^{25}$ exemplifica bem este tipo de perspectiva. Destinando-se às ciências cognitivas, é uma revista eletrônica gratuita que recebe artigos e, diferentemente do arXiv, possui um corpo editorial formado por um conjunto de especialistas de diferentes áreas e localidades. Este corpo editorial analisa os artigos e - aí reside seu grande diferencial - caso decida comentá-lo, o texto é publicado com o comentário e a resposta do autor já integrados. Se novas discussões forem desenvolvidas por outros autores, especialistas ou leitores (embora o comentário deste último também passe por avaliação de um corpo editorial), estas serão também publicadas, de forma que o debate torna-se constante e mais rápido. Assim, permitem-se a revisão de conceitos, o redirecionamento de pesquisas etc.

A este respeito, comenta Arlindo Machado*:

"A idéia que está por trás do modelo de Psycoloquy é que uma vez instituída a peer review (agora rebatizada de peer commentary) como um mecanismo de promoção da qualidade através da crítica permanente (e não como uma simples autoridade seletiva), o(s) próprio(s)

\footnotetext{
* Ver "Publicações científicas: da galáxia de Gutenberg à aldeia telemática". Disponível em: www.freudiana.com.br/escobar/ arlindomachado_publica.htm (referência número 7).
}

autor(es) pensará(ão) duas vezes antes de submeter à revista um trabalho vulnerável, ainda imaturo e pouco fundamentado. $\mathrm{O}$ risco agora não é mais o de não ser publicado, mas o de ficar exposto a uma crítica fulminante. Assim, o elemento diferencial da publicação eletrônica passa a ser outro: ele não está simplesmente na difusão mais rápida dos artigos e na facilidade de busca instantânea (search) em toda a literatura científica disponível. A essência mesma do meio eletrônico reside no feedback imediato, na estrutura bidirecional e na conseqüente possibilidade de diálogo, em uma palavra, na potencialidade de comunicação..."

\section{O LIBER}

O projeto Narrativas Digitais do Virtus - Laboratório de Hipermídia da Universidade Federal de Pernambuco tem realizado uma série de estudos também com o propósito de viabilizar a publicação eletrônica na Internet. Neste sentido, vêm desenvolvendo o Liber $^{26}$, que tem como objetivo permitir que o usuário possa publicar e acessar gratuitamente textos em formato digital.

Liber é uma palavra de origem latina que significa livro. Tal como originalmente concebida, esta palavra era aplicada à qualquer suporte onde estivesse fixado um pensamento, uma informação, podendo ser designado por livro um pergaminho, uma pedra, uma parede ${ }^{27}$.

O projeto Narrativas Digitais então retoma esta concepção mais genérica da palavra livro e apresenta o Liber como um espaço para organização do pensamento com características hipermídicas. Toma como referência pesquisas recentes em ferramentas narrativas, que apontam igualmente para a criação de um novo padrão em que textos, imagens e sons são acoplados em novas estruturas narrativas. Pretende, assim, afastarse do padrão do texto impresso e apontar o surgimento de um produto totalmente digital e diferenciado da tecnologia impressa.

No Liber, a inserção de documentos depende do preenchimento de formulário simples e a publicação se faz de forma rápida e fácil. O usuário conta ainda com as seções de edição, nas quais poderá excluir ou alterar informações relativas ao texto, e de acervo, onde qualquer usuário da Internet poderá, mediante consulta, acessar e comentar todos os documentos inseridos no Liber.

Publicar no Liber implica então assumir não somente a responsabilidade pelo processo de redação, mas também de edição, disponibilização e divulgação dos textos que o usuário inserir. 


\section{LOGIN, INSERIR, EDITAR E ACERVO}

Neste artigo, vamos nos deter à apresentação do Liber em termos destas quatro seções principais que constituem o Liber atualmente: login, inserir, editar e acervo.

A seção login deve ser a primeira das seções visitadas pelo usuário que queira iniciar o processo de publicação no Liber. É por meio dela que o usuário cria uma área reservada às suas publicações e garante seu direito de, com a inserção também de uma senha, inserir e editar seus próprios textos.

O usuário pode agora seguir à seção inserir, que é destinada à disponibilização de informações que ele só deverá acessar após colocar seu login e sua senha. Nesta seção, o usuário fornece informações relativas à obra (título e resumo) e à autoria (nome do autor, e-mail e resumo sobre o autor), em um formulário simples com cinco campos para preenchimento.

Na seção edição, uma área exclusiva para o autor que já dispõe de login e senha, o processo de publicação será concluído mediante inclusão do arquivo correspondente à obra já resumida anteriormente. Quando este procedimento é feito, o usuário poderá fazer o download completo do documento, inserir e consultar comentários diversos e, ainda, consultar uma breve apresentação a respeito do autor e da obra.

A seção edição permite ainda que (1) as informações referentes à obra e ao autor sejam corrigidas; (2) que sejam apagadas as obras já disponibilizadas pelo usuário e (3) que sejam apagados comentários sobre a obra enviados pelo usuários da Internet.

Finalmente, a seção busca permite que qualquer usuário conectado à web possa ter acesso direto às obras de seu interesse publicadas no Liber.

\section{Características gerais do Liber}

Como anteriormente mencionado, há iniciativas em todo o mundo hoje para viabilizar a publicação eletrônica. Sobre o Liber, vale a pena destacar algumas peculiaridades:

- rapidez no processo de divulgação de informações: há apenas um formulário e nele poucos campos a serem preenchidos;

- facilidade: instruções claras tornam o site acessível a autores de diferentes idades;

- gratuidade: o Liber não exige qualquer tipo de pagamento pela publicação de obras;
- interatividade: o usuário poderá contatar o autor e comentar a obra, enviando mensagens que poderão ser lidas por todos os usuários do Liber;

- edição: o autor poderá atualizar sua obra ou exclui-la;

- navegabilidade: com facilidade o usuário do Liber encontra um sistema de navegação em que se identificam facilmente os procedimentos possíveis de serem realizados;

- nacionalidade: no Brasil, poucos são os espaços abertos para disponibilização de textos eletrônicos com as características acima mencionadas. O Liber pretende, então, ampliar o espaço para publicações eletrônicas no Brasil, caracterizando-se como um produto de qualidade em língua portuguesa.

\section{CONSIDERAÇÕES FINAIS}

O Liber tem se caracterizado como um repositório de publicações. As primeiras obras disponibilizadas são fruto de parceria com a Editora Universitária. Naufrágio e Prosopopea, de Afonso Luiz Piloto e Bento Teyxeyra, respectivamente, publicadas em impresso por volta do início do século XVII, foram reeditadas pela Editora da UFPE em 1969. Três séculos depois, no início de 2001, ganharam no Liber sua versão eletrônica.

Por nascer em ambiente acadêmico, o Liber tem a expectativa de auxiliar especialmente estudantes e professores a superar os constantes obstáculos à publicação, incompatíveis com a contínua produção de documentos realizadas por professores, estudantes, funcionários e outros. A parceria com a Editora da UFPE, por exemplo, permitirá ao autor publicar sua obra nos formatos impresso e digital, simultaneamente. Em uma primeira etapa, o Liber publicará obras do acervo da Editora da UFPE e as publicações do Virtus. Em ambos os casos, as obras serão publicadas em formato PDF. Na próxima etapa do projeto, serão incorporadas novas tecnologias narrativas, com imagens e sons, e será viabilizada a abertura para o usuário da Internet.

A publicação digital é entendida no Liber como mais uma alternativa de incentivo à produção de conhecimentos e à reflexão crítica. Nossas pretensões, como laboratório que desenvolve tecnologias hipermídicas, é criar novas ferramentas no âmbito da publicação e, assim sendo, contribuir para a ampliação do universo de leitura e autoria.

Artigo aceito para publicação em 10-06-2002 


\section{Liber: alternativa para publicação eletrônica}

\section{REFERÊNCIAS}

1. DIRECTORY of electronic journals, newsletters and academic discussion lists. [S. 1.] : Association of Researches Libraries. Disponível em: < http://db.arl.org/foreword.html $>$.

2. BIBLIOTECA MIGUEL DE CERVANTES. Disponível em: < http:/ /www.cervantesvirtual.com $>$.

3. LITERATURE online. Disponível em: <lion.chadwyck.co.uk/html/ homenosub.htm $>$.

4. LITERATURA brasileira: textos literários em meio eletrônico. Disponível em: <http://www.cce.ufsc.br/ alckmar/literatura/ literat.html>.

5. ODLYZKO, Andrew M. Tragic loss or good riddance? the impending demise of traditional scholarly journals. International Journal Human-Computer Studies, v. 42, p. 71-122, 1995. Disponível em: <http://www.research.att.com/ amo/doc/tragic.loss.txt $>$.

6. CHARTIER, Roger. A aventura do livro: do leitor ao navegador. São Paulo: Unesp, 1998, p. 117.

7. MACHADO, Arlindo. Publicações científicas: da galáxia de Gutenberg à aldeia telemática. Disponível em: $<$ www.freudiana.com.br/ escobar/arlindomachado_publica.htm >.

8. BUSH, Vannevar. As we may think. Atlantic Monthly, July, 1945. Disponível em: <http://www.theatlantic.com/unbound/flashbks/ computer/bushf.htm $>$.

9. SENA, Nathália Kneipp. Open archives: caminho alternativo para a comunicação científica. Ciência da Informação, Brasília, v. 29, n. 3, p. 71-78, set./dez. 2000.

10. EPRINTS ou preprints. Disponível em: < http://lib-www.lanl.gov/ libinfo/preprints.htm>.

11. ARXIV. Disponível em: <http://www.arxiv.org $>$.

12. DARNTON, Robert. Disponível em: <http://www.theaha.org/ prizes/gutenberg/rdarnton2.cfm $>$.

13. AUGUSTO, Sérgio. A salvação do livro na tela do computador. Disponível em: <http://sites.uol.com.br/vello/ebook.htm>.
14. LITERATURA sul-rio-grandense. Disponível em: <http:// www.geocities.com/Athens/Acropolis/2776/literatura.html>.

15. PÓlVORA, Hélio. Jornal de contos. Disponível em: <www.enet.com.br/contos>.

16. MORAES, Dênis de. O concreto e o virtual. Rio de Janeiro: DP \& A Editora, 2001, p. 101.

17. GUTENBERG-E. Disponível em: < http://www.theaha.org/prizes/ gutenberg $>$.

18. MENEZES, Estera Muszkat; COUZINET, Viviane. O interesse das revistas brasileiras e francesas de biblioteconomia e ciências da informação pela revista eletrônica no período de 1990-1999. Ciência da Informação, Brasília, v. 28, n. 3, p. 278-285, set./dez. 1999.

19. ARQUIVOS abertos. Disponível em: <http://www.ibict.br>.

20. LEVY, Pierre. As tecnologias da inteligência: o futuro do pensamento na era da informática. São Paulo: Editora 34, 1998.

21. HIPERTRAMAS. Disponível em: <http://www.hipertramas. cjb.net $>$.

22. VIRTUS: laboratório de hipermídia. Disponível em: $<$ http:// www.virtus.ufpe.br>. <http://www.projetovirtus.com.br $>$.

23. CUNHA FILHO, Paulo Carneiro; NEVES, André Menezes Marques das; PINTO, Rômulo César Gonçalves. O projeto virtus e a construção de ambientes virtuais de estudo coorperativo. In: MAIA, Carmem. (Org). Educação a distância no Brasil na era da Internet. São Paulo : Anhembi Morumbi, 2000.

24. NEVES, André; CUNHA FILHO, Paulo Carneiro. Projeto virtus: educação e interdisciplinaridade no ciberespaço. Recife : Editora Universitária da UFPE/São Paulo : Universidade Anhembi Morumbi, 2000.

25. PSYCHOLOQUY. Disponível em: <http://www.cogsci.soton. ac.uk/psycoloquy/>.

26. LIBER. Disponível em: <http://www.virtus.ufpe.br/teses>.

27. MACHADO, Arlindo. Pré-cinemas e pós-cinemas. Campinas : Papirus, 1997. 